\section{Comment}

Women under the age of 20 years constituted a small minority of those attending the colposcopy clinic. This mainly reflects the small number of women of this age group who were screened. During the period of the study $46 / 1000$ smears in girls under the age of 20 years were abnormal (range $41 / 1000$ in 1982 to $69 / 1000$ in 1985), the pick up rate for all ages being 65/1000 during that period (personal communication $M$ Colquhoun, department of cytopathology, University of Edinburgh). This is two to three times the pick up rate reported by Sadeghi. ${ }^{5}$ It is also of interest that in our study over half the patients had evidence of cervical human papillomavirus infection and that $68 \%$ of patients with external genital warts also showed cervical intraepithelial neoplasia. Significantly, two thirds of patients with vulval warts and normal findings on cervical cytology had cervical intraepithelial neoplasia, koilocytosis, or both. It is difficult to escape the conclusion that cervical screening may not be detecting all precancerous lesions and that patients with external genital warts should have colposcopic assessment even if their cervical cytology is reported as normal.

The discovery of premalignant lesions of the cervix in increasing numbers of teenagers is worrying. While none of our teenagers had invasive disease, $25 \%$ of the whole group $(31 \%$ of those with abnormal cervical cytology) had cervical intraepithelial neoplasia grade III, which supports a policy of especial vigilance in this group and suggests that the onset of cervical screening should start from an earlier age than currently recommended.

1 Roberts A. Cervical cytology in England and Wales 1965-80. Health Trends 1982;14:41-5.

2 Patterson MEL, Peel KB, Joslin CAF. Cervical smear histories of 500 women with invasive cancer in Yorkshire. Br Med f 1984;289:896-8.

3 Department of Health and Social Security. Health services development. Screening for cervical cancer. London: DHSS, 1984 (HC 84 (17).)

4 Intercollegiate working party on cervical cytology screening. Report. London: Royal College of Obstetricians and Gynaecologists, 1987:8.

5 Sadeghi SB, Hsieh EW, Gunn SW. Prevalence of cervical intraepithelial neoplasia in sexually active teenagers and young adults. Am $\mathcal{f}$ Obstet Gynecol 1984;148:726-9.

(Accepted 14 March 1988)

\title{
Relation between falciparum malaria and HIV seropositivity in Ndola, Zambia
}

\author{
Oscar O Simooya, Rosemary M Mwendapole, \\ Seter Siziya, Alan F Fleming
}

Tropical Diseases Research Centre, PO Box 71769, Ndola, Zambia Oscar O Simooya, MSC senior scientific officer, clinical pharmacology department Rosemary M Mwendapole, MSC, scientific officer, immunology department Seter Siziya, MSC, biostatistician

Alan F Fleming, FRCPATH, deputy director (research)

Correspondence and requests for reprints to: $\mathrm{Dr}$ O O Simooya, Department of Therapeutics, Royal Hallamshire Hospital, Sheffield S10 2JF.
AIDS and the human immunodeficiency virus (HIV) have now been documented in Zambia.' This development poses a formidable challenge to health authorities in a country where several other illnesses, chiefly malaria, continue to cause great morbidity and mortality. Our main objective was to determine whether infection with HIV increases the risk or severity of infection with falciparum malaria in patients aged 12 and above.

\section{Patients, methods, and results}

The study was conducted at the Ndola Central Hospital in January 1987. Patients aged 12 and above presenting with symptoms suggestive of malaria were included. Symptoms included fever, chills, rigors, headaches, joint pains, myalgia, acute diarrhoea, and vomiting. None had manifestations of AIDS.

Each patient was screened for malaria parasitaemia,

Numbers of patients with and without parasitaemia with antibodies to HIV and P falciparum

\begin{tabular}{|c|c|c|c|c|c|c|}
\hline \multirow[b]{2}{*}{$\begin{array}{l}\text { P falciparum } \\
\text { antibody }\end{array}$} & \multicolumn{2}{|c|}{$\begin{array}{c}\text { Patients with } \\
\text { parasitaemia }(n=67)\end{array}$} & \multicolumn{2}{|c|}{$\begin{array}{l}\text { Patients without } \\
\text { parasitaemia }(n=103)\end{array}$} & \multicolumn{2}{|c|}{ Significance } \\
\hline & $\begin{array}{l}\text { HIV positive } \\
\qquad(\mathrm{n}=8)\end{array}$ & $\begin{array}{l}\text { HIV negative } \\
(\mathrm{n}=59)\end{array}$ & $\begin{array}{l}\text { HIV positive } \\
\quad(\mathrm{n}=20)\end{array}$ & $\begin{array}{l}\text { HIV negative } \\
\quad(\mathrm{n}=83)\end{array}$ & $x^{2}$ & $\mathrm{p}$ Value \\
\hline Positive & 7 & 56 & 13 & 61 & 0.00 & 0.97 \\
\hline Negative & 1 & 3 & 7 & 22 & 0.23 & 0.60 \\
\hline
\end{tabular}

specific malarial antibodies, and HIV antibodies. Parasitaemia was determined by examining blood films stained with Giemsa under a light microscope and titres of antibody to Plasmodium falciparum by an indirect fluorescent antibody technique. HIV antibody was determined with the Wellcozyme immunoassay (Wellcome). All serum samples that gave positive results were retested, and if positive results were found again the samples were tested in an enzyme linked immunosorbent assay (ELISA) that used a bacterially synthesised polypeptide homologous with a hybrid of p24 and gp41 of HIV (Hoffman La Roche) as antigen.

Altogether 172 patients were studied. Two infected with $P$ malariae were excluded from the analysis. Of the remaining 170 (107 males, 63 females), 67 (39\%, $95 \%$ confidence interval 32.06 to 46.75 ) had falciparum malaria. Twenty eight (18 males, 10 females) (17\%, $95 \%$ confidence interval 10.80 to 22.04 ) were positive for HIV antibody. Parasitaemia was less common among those with HIV antibodies than among those without (8 out of $28(29 \%) v 59$ out of $142(42 \%)$, respectively), but the difference was not significant (table). The $\log _{\mathrm{e}}$ mean parasite density in blood slides showing parasitaemia was higher in patients who were negative for HIV antibody than in those who were positive for HIV antibody, but the difference was not significant $\left(\log _{\mathrm{e}}\right.$ mean differencee 2.43 , SE 1.4113 ; $\mathrm{p}<0 \cdot 10)$. Sixty three of the $67(94 \%)$ patients with parasitaemia and 74 of the $103(72 \%)$ without had considerable antibody titres to $P$ falciparum. No significant differences existed in antibody titres to $P$ falciparum in patients who were positive for HIV antibody and in those who were negative whether or not they had parasitaemia.

\section{Comment}

Our study was conducted during the season of malarial transmission, so the rate of parasitaemia of $39 \%$ was expected. The proportion of patients positive for HIV antibody $(17 \%)$ was similar to that found among febrile patients. 'The prevalence of malarial parasitaemia in patients with HIV antibodies was lower than that in patients without such antibodies, and differences in densities of parasites also did not provide evidence of increased susceptibility to malaria in patients infected with HIV.

A significant association between malaria and infection with HIV has been suggested ${ }^{2}$ but is now thought to have been due to many false positive results with earlier ELISAs and to difficulties in interpreting Western blots. ${ }^{3}$ The Wellcozyme immunoassay is newer and $100 \%$ specific $^{+}$(R M Mwendapole et al, second international symposium on AIDS and associated cancers, Naples, Italy, 1987). Our results showed no cross reaction between the antibody to $P$ falciparum by the indirect fluorescent antibody technique and the HIV antibody by the Wellcozyme immunoassay nor were false positive results with the Wellcozyme immunoassay associated with malarial parasitaemia. 
There was no apparent failure of the humoral response to malaria associated with infection with HIV, but as we observed only patients aged 12 and above a study of the acquisition of immunity in infants positive and negative for HIV antibody might be of interest, as would a study in patients with terminal AIDS. Twenty patients had symptoms suggestive of malaria but gave negative results for parasites and positive results for HIV antibody. This suggests that many patients with HIV infection may be presenting with an illness similar clinically to malaria before AIDS related complex or AIDS is recognisable.

We thank the hospital doctors for referring their patients to us and the Ministry of Health for permission to publish the findings of this study. The research centre is funded by the government of the Republic of Zambia and by the joint United Nations Development Programme, World Bank, and World Health Organisation special programme for research and training in tropical diseases.

1 Melbye M, Njelesani EK, Mukelabai K, et al. Evidence for heterosexual infection and related conditions in Lusaka, Zambia. Lancet 1986;i:1113-5.

2 Biggar RJ, Gigase PL, Melbye M, et al. ELISA HTLV retrovirus antibody reactivity associated with malaria and immune complexes in healthy Africans. reactivity associated 1985 ;ii:520-3.

3 Hunsmann G, Schneider J, Wendler I, Fleming AF. HTLV positivity in Africans. Lancet 1985;ii:952-3.

4 Reesink WH, Lelie PN, Huisman JG, et al. Evaluation of six enzyme immunoassays for antibody against human immunodeficiency virus. Lancet 1986;ii:483-6.

(Accepted 28 March 1988)

\section{Does low entry of cystic duct predispose to stones in the common bile duct?}

\section{P C Bornman, R E Kottler, J Terblanche, A N Kingsnorth, J E J Krige, I N Marks}

University of Cape Town and Groote Schuur

Hospital, Cape Town,

PC Bornman, FRCSED, head, surgical gastroenterology R E Kottler, FRCR, head, department of radiology J Terblanche, FRCs, head, department of surgery

A N Kingsnorth, FRCS, visiting lecturer from

University of Liverpool

J E J Krige, FRCSED, senior specialist, department of surgery

IN Marks, FRCPED, head, gastrointestinal clinic

Correspondence to: Professor PC Bornman, Gastrointestinal Clinic, Groote Schuur Hospital, Observatory, 7925 Cape Town, South Africa. South Africa

In patients undergoing endoscopic papillotomy for stones in the bile duct the cystic duct often seems to enter the bile duct low down from the left (see fig $(a)$ ). To substantiate this impression the site of entry of the cystic duct in patients with stones in the bile duct was compared with that in patients with stones in the gall bladder and that in a group of control patients.

\section{Patients, methods, and results}

The position of the entry of the cystic duct into the common hepatic duct was studied in a consecutive series of $\mathbf{5 0}$ patients with stones in the bile duct by reviewing endoscopic retrograde cholangiograms. Sixteen patients had a cholecystectomy; associated stones were seen in 22 of the 34 with intact gall bladders. These results were compared with the routine operative cholangiograms of 50 patients with stones in the gall bladder but no evidence of stones in the bile duct and with those of 50 control patients with abdominal pain and normal results from endoscopic retrograde cholangiopancreatography.

The figure $(b)$ shows the segments of the bile duct measured. To overcome discrepancies due to the type of cholangiogram distances from the ampulla to the

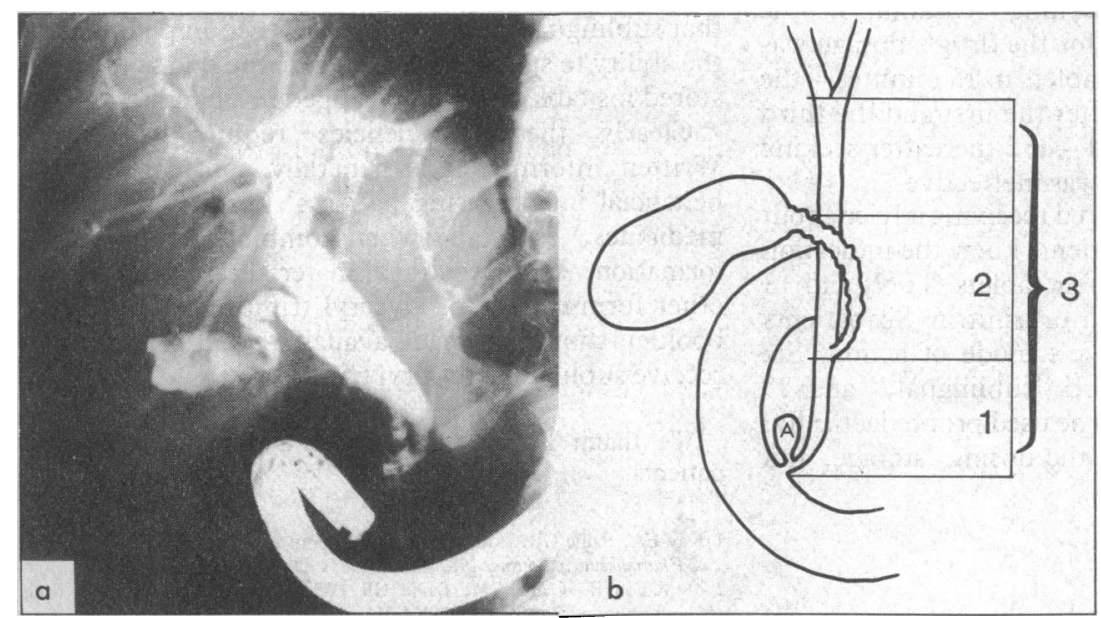

(a) Left sided entry of cystic duct at level of ampulla of Vater. (b) Measurements of segments of bile duct: 1 ampulla of Vater to entry of cystic duct, 2 contiguous segment of cystic duct and common hepatic duct, and 3 total length of bile duct. $A=$ Ampullary diverticulum entry of the cystic duct (segment 1) and the contiguous segment of the cystic duct (segment 2) were expressed as ratios of the total length of the bile duct (segment 3). Periampullary diverticula were also documented. The unpaired Student's, $\chi^{2}$, and Fisher's exact tests were used for statistical analyses when appropriate.

The mean age of the group with stones in the bile duct was 65 (SD 16), which was higher than that of the group with stones in the gall bladder $(52(13 \cdot 2))$ and that of control patients $(47(15.9))(p<0.001$ in both cases). The group with stones in the bile duct contained more men than the group with stones in the gall bladder ( $n=24$ and 10, respectively; $p<0.001)$.

The ratio of segments 1 to 3 was significantly lower in the group with stones in the bile duct, being 0.28 $(0.20)$ compared with $0.55(0.16)$ in the group with stones in the gall bladder and $0.54(0.19)$ in the control group ( $<<0.001$ in both cases). Conversely, the ratio of segments 2 to 3 was significantly higher in the group with stones in the bile duct, being $0.43(0.15)$ compared with $0.21(0.14)$ in the group with stones in the gall bladder and $0.21(0.15)$ in the control group $(p<0.001)$. Low entry of the cystic duct was defined as less than $3.5 \mathrm{~cm}$ from the ampulla and was more common in the group with stones in the bile duct $(n=28)$ than in the group with stones in the gall bladder or in the control group $(n=12$ and 5, respectively; $\mathrm{p}<0.005$ ). Ampullary diverticula were also significantly more common among those with stones in the bile duct ( 17 out of 50 ) than among control patients (three out of 50) $(\mathrm{p}<0.001)$, but no clear association was found between ampullary diverticula and low entry of the cystic duct. The combination of a left sided and low entry of the cystic duct into the bile duct was more common in patients with stones in the bile duct (17 out of 50$)$ than in those with stones in the gall bladder (three out of 50) $(p<0.001)$ or those in the control group (four out of 50) $(p<0.003)$. This combination was noted in all nine patients aged less than 30 and in all five black patients (mean age 42, range 22-52) with stones in the bile duct in our total experience with bile duct stones.

\section{Comment}

Our study shows that stones in the bile duct are commonly associated with a low and often left sided entry of the cystic duct into the bile duct. The pathogenetic relevance of this is reinforced by the invariable finding of this anatomical variant in young and in black patients, in whom stones in the bile duct are otherwise rare. Although the mechanism for the formation of such stones is uncertain, stasis with colonisation and the formation of calcium bilirubinate stones is probable. ${ }^{2}$ Alternatively, low entry of the cystic duct may lead to increased retrograde pressure 